\title{
Delayed Awakening after use of Dexmedetomidine
}

\author{
MAMOONA SHAIKH ${ }^{1}$, JAMIL AHMED ${ }^{2}$, JUWEREYA MEMON³, KAUSER SHAIKH ${ }^{4}$, SHAHID KHAN ${ }^{5}$, GHULAM NABI \\ MMEON 6 \\ ${ }^{1}$ Senior Registrar, Anesthesia, Isra University Hyderabad \\ ${ }^{2}$ Associate Professor of Anesthesia, Isra University Hyderabad \\ ${ }^{3}$ Assistant Professor of Surgery, Isra University, Hyderabad \\ ${ }^{4}$ General Surgeon, Shah Bhittai Hospital Hyderabad \\ ${ }^{5}$ Assistant Professor of Orthopedics, Isra University Hyderabad \\ ${ }^{6}$ Professor of Anesthesia, Isra University Hyderabad \\ Correspondence to Dr. Mamoona Shaikh
}

\section{SUMMARY}

Dexmedetomidine (DEX) is currently being used as a premedication for anxiolysis, as an adjunctive drug both during and after surgery and as an adjunct to attenuate emergence agitation, postoperative pain, and shivering. It is an alpha-2 agonist which is 8 times more potent than clonidine and is also has sympatholytic effects ${ }^{1}$. It is also being used as an adjunct in central neraxial blocks to enhance the quality and to prolong the duration of the block $^{2,3}$. Its use in peripheral nerve blocks is also reported.

Keywords: Anxiolysis, fibroadenoma, agitation

\section{CASE REPORT}

We present to you a case of a 20 years old girl who presented as a day case for removal of multiple fibroadenomas from her right breast. She weighted $45 \mathrm{~kg}$, was heighted $147 \mathrm{~cm}$. She was labeled as ASA 1 and had no any previous anaesthetic records. Vitals taken in the preoperative area were normal and her consent was obtained for errecter spinae plane (ESP) block for postoperative analgesia.

She was taken to the OR and premedicated with $3 \mathrm{mg}$ nalbuphine and 40mg lignocaine intravenously and coinduction done with $20 \mathrm{mg}$ ketamine and $60 \mathrm{mg}$ propofol. Atracurium $20 \mathrm{mg}$ was given and after 3 minutes of controlled mask ventilation with $100 \%$ oxygen and $2 \%$ isoflurane, patient was intubated with $7.0 \mathrm{~mm}$ endo-tracheal tube and surgery was commenced. She remained vitally stable throughout the surgery and the surgery took place uneventfully. The procedure lasted for 1 hour and 15 minutes. At the end of the procedure the patient was turned to lateral decubitus and an ESP block was done at the level of T4 on right side with $20 \mathrm{mls}$ of $0.2 \%$ bupivacaine and $50 \mathrm{mcg}$ of dexmedetomidine. As soon as the patient was turned to supine position again, her heart rate dropped from $86 \mathrm{bpm}$ to $49 \mathrm{bpm}$ and Also developed hypotension for which $0.6 \mathrm{mg}$ atropine and rapid fluid infusion was given and the heart rate increased to $101 \mathrm{bpm}$ and her hypotension also subsided. Patient regained spontaneous efforts after with isoflurane was discontinued and after reversing the patient she was extubated in awake plane.

However after about 5 minutes of being on the recovery area, the patient became drowsy and difficult to arouse with painful stimulus. Also patient had sluggish movements of both upper limbs while she could raise her legs easily. She also developed miosis in both eyes however there was no any respiratory depression.

A conclusion was made of dexmedetomidine passing into the epidural space from ESP. the patient remained in

Received on 11-05-2021

Accepted on 21-09-2021 the PACU for about six hours, at the end of which she was fully conscious, conversing, pain free and could move her all four limbs easily. The patient was followed up next day. The patient was pain free the entire day and the night of surgery and had no any complains.

\section{DISCUSSION}

Although dex is a safe drug in terms of minimal respiratory depression, it is known for causing bradycardia and sedation which could lead to delayed awakening or prolonged PACU discharge times ${ }^{4,5}$. The regulation of sedation, autonomic function, and pupillary reaction are all inter-related and controlled centrally at the locus coeruleus (LC) due to stimulation of presynaptic a2Aadrenergic receptors by dexmedetomidine. Any pharmacological alteration to this neuronal circuitry would affect the activity at the LC and clinically result in changes in the level of sedation, heart rate, arterial pressure, and pupil size ${ }^{7-10}$. Hence in our case patient developed not only the known side effects but also a rare and not commonly known adverse effect secondary to dex (miosis). A similar case was presented in the British Journal of Anaesthesia with striking similarities to our case report ${ }^{11}$.

\section{CONCLUSION}

This case report teaches us to have a wide vision and sometimes a paradigm shift when managing a patient with delayed awakening and prolonged recovery room discharge times. Being an anaesthesiologist, it is of utmost importance to keep in the back of mind even the unusual sequelae of drugs used in our daily practice for safe patient care and timely management of complications.

\section{REFERENCES}

1. Kamibayashi T, Maze M. Clinical uses of alpha-2 adrenergic agonists. Anaesthesiology. 2000;93(5):1345-1349.

2. Salgado PF, Sabbage AT, Silva P. Synergistic effect between dexmedetomidine and $0.75 \%$ ropivacaine in epidural anaesthesia. Rev Assoc Med Bras. 2008;54(2):110-115. 
3. Kalso EA, Poyhia R, Rosenberg PH. Spinal antinociceptors by dexmedetomidine, a highly selective alpha 2 agonists. Pharmacol Toxicol. 1991;68(2):140-143.

4. Olutoye OA, Glover CD, Diefenderfer JW, et al. The effect of intraoperative dexm edetom idine on postoperative analgesia and sedation in pediatric patients undergoing tonsillectom y and adenoidectom y. Anesth. Analg. 2010 Aug;111(2):490-5.

5. Phelps JR, Russell A, Lupa M C, et al. High-dose dexm edetom idine for noninvasive pediatric procedural sedation and discharge readiness. Paediatr. Anesth. 2015 Sep;25(9):877-82.

6. amuels ER, Szabadi E. Functional neuroanatomy of the noradrenergic locus coeruleus: its roles in the regulation of arousal and autonomic function part II: physiological and pharmacological manipulations and pathological alterations of locus coeruleus activity in humans. Curr Neuropharmacol 2008; 6: 254-85
7. Hou RH, Freeman C, Langley RW, Szabadi E, Bradshaw CM. Does modafinil activate the locus coeruleus in man? Comparison of modafinil and clonidine on arousal and autonomic functions in human volunteers. Psychopharmacology (Berl) 2005; 181: 537-49

8. Hou RH, Scaife J, Freeman C, Langley RW, Szabadi E, Bradshaw CM. Relationship between sedation and pupillary function: comparison of diazepam and diphenhydramine. $\mathrm{Br} \mathrm{J}$ Clin Pharmacol 2006; 61: 752-60

9. Artigas C, Redondo JI, Lopez-Murcia MM. Effects of intravenous administration of dexmedetomidine onintraocular pressure and pupil size in clinically normal dogs. Vet Ophthamol 2012; 15(Suppl. 1): 79-82

10. Goyal,V. K. Sharma, N. K. Singh. Miosis with dexmedetomidine: every little helps, every picture tells a story. 10.1093/bja/aeu126. 